\title{
Diversity and surge in abundance of native parasitoid communities prior to the onset of Torymus sinensis on the Asian chestnut gall wasp (Dryocosmus kuriphilus) in Slovenia, Croatia and Hungary
}

\author{
Katarina Kos ${ }^{1}$ Nikola Lackovićc ${ }^{4}$ George Melika ${ }^{3}$. \\ Dinka Matošević
}

Received: 26 November 2019 / Accepted: 30 June 2020 / Published online: 31 July 2020

(C) The Author(s) 2020

\begin{abstract}
Since the rapid spread of the Asian chestnut gall wasp (ACGW) throughout south-east Europe in the last few years, the possibilities of its control have been increasingly investigated. Due to constraints in available suppression measures in forest stands, biological control is recognized as the most suitable action to lower the abundance of the new invasive pest. Torymus sinensis, as a specialized parasitoid chalcid wasp of ACGW, was introduced to suppress the pest in Italy in 2005, and later in Croatia, Hungary (2014) and Slovenia (2015). We investigated the native parasitoid complex associated with ACGW in Slovenia, Croatia and Hungary over 8 years of sampling. We found 41 species of native parasitoids, eight of which are the first records on ACGW in Europe, adding up to a total of 51 species known to parasitize ACGW. These findings represent a large complex
\end{abstract}

Project funding: The work was supported by The Phytosanitary Administration of the Republic Slovenia and by Diagnostic and Prognostic Service (IPP) of the Ministry of Agriculture of the Republic of Croatia.

The online version is available at http://www.springerlink.com.

Corresponding editor: Tao Xu.

Katarina Kos

katarina.kos@bf.uni-lj.si

1 Department of Agronomy, Biotechnical Faculty, University of Ljubljana, Jamnikarjeva 101, 1000 Ljubljana, Slovenia

2 Department for Forest Protection and Game Management, Croatian Forest Research Institute, Cvjetno naselje 41, 10450 Jastrebarsko, Croatia

3 Plant Health and Molecular Biology Laboratory, Directorate of Plant Protection, Soil Conservation and Agri-environment, National Food Chain Safety Office, Budaörsi u. 141-145, Budapest 1118, Hungary

4 Antuna Mihanovića 4, 10450 Jastrebarsko, Croatia of cynipid-parasitoid fauna. Moreover, the abundance of native parasitoid populations on ACGW have demonstrated a temporal surge between the invasion of a new alien host (ACGW) and the onset of its specialized parasitoid, T. sinensis. Our results indicate that the introduced parasitoid acts as a very successful biocontrol of ACGW, outcompeting native parasitoids. This outcome should be considered as beneficial through the maintenance of ecological balance in affected forest ecosystems.

Keywords Invasive pest - ACGW - Biological control · Native parasitoids $\cdot$ Torymus sinensis

\section{Introduction}

The Asian chestnut gall wasp Dryocosmus kuriphilus Yasumatsu (ACGW) is a member of a diverse group of gall wasps (Hymenoptera, Cynipidae), and is one of the most important pests of the sweet chestnut Castanea sativa Mill., the Japanese chestnut $C$. crenata Siebold \& Zucc., the Chinese chestnut $C$. mollisima Blume, the American chestnut $C$. dentata (Marshall) Borkh. and their hybrids worldwide (EPPO 2005; Aebi et al. 2006). The ACGW is a parthenogenetic species with one generation per year, and females lay eggs in the buds of chestnuts in the summer. The overwintering stage is the first-instar larvae that induce gall formation the following spring (Ôtake 1989). One of the reasons why this alien species became invasive was the lack of natural enemies in the invaded area (Matošević and Melika 2013). Among the various factors (parthenogenesis, abundant egg laying), the inactivity of native parasitoids occurred during the early stages of infestation, favouring the rapid spread of this new phytophagous insect in Europe. Parasitoid insects are commonly considered to be host-specific and thus represent one 
of the most used natural enemies for biological pest control (Godfray 1994). There are numerous parasitoid species that have a wide host range that may not be consistent across the distribution of an entire species, while host adaptation can occur in parasitoid populations and thus restrict the potential host range (Antolin et al. 2006; Henry et al. 2008; Zepeda-Paulo et al. 2013). However, within the range of all potential hosts, not all are equally preferred and/or become susceptible to the development of parasitoids (Desneux et al. 2009). The community of gall wasp parasitoids, especially on oaks, is very abundant owing to the species richness of oak gall wasps (Askew et al. 2013). Parasitoids reared from cynipid galls are usually specific to cynipid wasps, and a certain number can adapt to the new abundant alien host, D. kuriphilus (Askew et al. 2013). The reported parasitism rates of native parasitoids were too low, rendering them ineffective in controlling the growing populations of ACGW (Matošević and Melika 2013; Quacchia et al. 2013; Kos et al. 2015; Colombari and Battisti 2016).

In Europe, studies on native parasitoid recruitment were only recorded for a few countries: Italy, Croatia, Hungary, Slovenia and Spain. Within six families (Eulophidae, Eupelmidae, Eurytomidae, Ormyridae, Pteromalidae and Torymidae), 31 species were found in Italy (Aebi et al. 2007; Speranza et al. 2009; Boriani et al. 2013; Panzavolta et al. 2013; Quacchia et al. 2013; Colombari and Battisti 2016). Matošević and Melika (2013) reported 15 species from five families in Croatia, Kos et al. (2017) found 35 native species in Slovenia, Kriston et al. (2014) and Melika et al. (2013) reported 11 species in Hungary and Jara-Chiquito et al. (2016), 14 species in Spain.

The rapid recruitment of oak gall cynipid parasitoids to ACGW occurred in Europe. Nevertheless, the actual emergence rate of native parasitoids on ACGW remains low, mainly due to a mismatch between the phenology of gall development and emergence time of native parasitoids (Aebi et al. 2006, 2007).

The aim of this research was to provide comprehensive information on the species parasitizing ACGW in Europe and show the species-rich complex of native parasitoids in Slovenia, Croatia and Hungary. As ACGW became established in new environments, it recruited several species of parasitoids associated primary with oak gall wasps.

\section{Materials and methods}

A survey for chalcid wasp parasitoid recruitment on ACGW was carried out over an 8-year period (2010-2017) in Slovenia, Croatia and Hungary. In Slovenia, data for the entire 8 years are provided (2010-2017), while in Croatia and Hungary data are available from 2013 to 2015 . The differences in sampling are due to logistical problems. However, we tried to unify and present the data so that valid conclusions could be made.

Sampling of ACGW galls occurred from February to April (overwintering galls), and from late May to mid-June (collecting newly formed galls) from 2010 to 2017. A total of 137,511 galls (Slovenia 98,267, Croatia 22,589 and Hungary 16,655) were collected from 57 locations in all three countries and in all sampling years in the main chestnut orchards and stands in each of the three countries. They were randomly collected by hand and with a tree cutter up to the height of $2.5 \mathrm{~m}$. The number of galls varied among years and locations depending on the rate of infestation. Galls were placed in nylon bags and transported to the entomological laboratories, the Laboratory of Phytomedicine at the Biotechnical Faculty in Ljubljana (Slovenia), Croatian Forest Research Institute in Jastrebarsko (Croatia), and the Plant Health and Molecular Biology Laboratory of the National Food Chain Safety Office in Budapest (Hungary). They were stored at room temperature in plastic mass rearing boxes, checked daily until the wasps emerged and after emergence, wasps from each sample were preserved in 70\% ethanol and identified at the Plant Health and Molecular Biology Laboratory in Budapest. Adult parasitoid identification was based on the key for Chalcidoidea families and genera (Goulet and Huber 1993).

In 2016 and 2017, very few galls were collected at certain locations in Slovenia due to severe spring frosts when most of new (yet forming) galls were destroyed. In Croatia and Hungary, no galls were collected in these years.

It is acknowledged that the data is not uniform (not the same sampling periods nor the same number of collected galls) in our research for Slovenia, Croatia and Hungary but we believe that it is justified to present this data as there are several new host-parasitoid records that add to the knowledge of these interactions in Europe. In order to have a complete overview of data on native parasitoids found on alien ACGW, Table 1 includes native parasitoids collected during this research as well as data already published (Matošević and Melika 2013; Melika et al. 2013; Kos et al. 2015). The inclusion of already published data with the original data of this research provides a complete overview of native parasitoid complex on ACGW prior to the arrival of the introduced alien parasitoid Torymus sinensis Kamijo (Hymenoptera: Torymidae) in Slovenia, Croatia and Hungary.

As the number of galls collected varied according to different rates of the infestation within years and in locations, and as the sampling effort was different among countries, the number of emerged specimens of native parasitoids and $T$. sinensis was standardized to 100 galls: standardized emergence rate $(\mathrm{er})=$ (number of parasitoids/total number of galls per sample) $\times 100$ (Quacchia et al. 2013). In addition, using a Chi square test, the sex ratio of emerged parasitoid 
Table 1 Number of specimens, sex ratio and gall age ratio of native parasitoid species emerged from ACGW (Dryocosmus kuripilus); numbers represent combined data from Slovenia, Croatia and Hungary from 2010 to 2017

\begin{tabular}{|c|c|c|c|c|c|c|c|c|c|c|}
\hline No. & Parasitoid species & Sum specimens & sum $\mathrm{m}$ & $\operatorname{sum} \mathrm{f}$ & F RATIO & chi2 & $\exp 50 / 50$ & $p$ value & SUM old & SUM new \\
\hline 1 & Aprostocetus biorrhizae & 4 & 0 & 4 & 4 & 2.00 & 2 & 0.1573 & 4 & 0 \\
\hline 2 & Aprostocetus aethiops & 2 & 2 & 0 & -2 & 1.00 & 1 & 0.3173 & 2 & 0 \\
\hline 3 & Aprostocetus glandicola & 1 & 1 & 0 & -1 & 0.50 & 0.5 & 0.4795 & 1 & 0 \\
\hline 4 & Aulogymnus skianeuros & 25 & 7 & 18 & 11 & 2.42 & 12.5 & 0.1198 & 19 & 6 \\
\hline 5 & Baryscapus sp. & 29 & 0 & 29 & 29 & 14.50 & 14.5 & $0.0001 * * *$ & 29 & 0 \\
\hline 6 & Bootanomyia dorsalis & 1573 & 538 & 1035 & 497 & 78.52 & 786.5 & $\mathbf{0 . 0 0 0 0} * * *$ & 54 & 1519 \\
\hline 7 & Bootanomyia dumicola & 1 & 0 & 1 & 1 & 0.50 & 0.5 & 0.4795 & 0 & 1 \\
\hline 8 & Bootanomyia stigmatizans & 1 & 1 & 0 & -1 & 0.50 & 0.5 & 0.4795 & 0 & 1 \\
\hline 9 & Cecidostiba fungosa & 23 & 3 & 20 & 17 & 6.28 & 11.5 & $0.0122 *$ & 1 & 22 \\
\hline 10 & Cecidostiba semifascia & 3 & 2 & 1 & -1 & 0.17 & 1.5 & 0.6831 & 3 & 0 \\
\hline 11 & Closterocerus trifasciatus & 1 & 0 & 1 & 1 & 0.50 & 0.5 & 0.4795 & 0 & 1 \\
\hline 12 & Eupelmus annulatus & 1435 & 545 & 890 & 345 & 41.47 & 717.5 & $0.0000 * * *$ & 404 & 1031 \\
\hline 13 & Eupelmus splendens & 16 & 2 & 14 & 12 & 4.50 & 8 & $0.0339 *$ & 14 & 2 \\
\hline 14 & Eupelmus urozonus & 2149 & 695 & 1454 & 759 & 134.03 & 1074.5 & $0.0000 * * *$ & 393 & 1756 \\
\hline 15 & Eupelmus vesicularis & 4 & 0 & 4 & 4 & 2.00 & 2 & 0.1573 & 0 & 4 \\
\hline 16 & Eurytoma brunniventris & 333 & 162 & 171 & 9 & 0.12 & 166.5 & 0.7273 & 180 & 153 \\
\hline 17 & Eurytoma pistaciae & 266 & 103 & 163 & 60 & 6.77 & 133 & $0.0093 * *$ & 86 & 180 \\
\hline 18 & Mesopolobus albitarsus & 7 & 0 & 7 & 7 & 3.50 & 3.5 & 0.0614 & 3 & 4 \\
\hline 19 & Mesopolobus amaenus & 14 & 1 & 13 & 12 & 5.14 & 7 & $0.0233^{*}$ & 0 & 14 \\
\hline 20 & Mesopolobus dubius & 13 & 3 & 10 & 7 & 1.88 & 6.5 & 0.1698 & 0 & 13 \\
\hline 21 & Mesopolobus fasciiventris & 42 & 15 & 27 & 12 & 1.71 & 21 & 0.1904 & 5 & 37 \\
\hline 22 & Mesopolobus sericeus & 688 & 204 & 484 & 280 & 56.98 & 344 & $0.0000 * * *$ & 1 & 687 \\
\hline 23 & Mesopolobus tarsatus & 28 & 4 & 24 & 20 & 7.14 & 14 & $0.0075^{* *}$ & 7 & 21 \\
\hline 24 & Mesopolobus tibialis & 722 & 248 & 474 & 226 & 35.37 & 361 & $0.0000 * * *$ & 5 & 717 \\
\hline 25 & Ormyrus nitidulus & 137 & 67 & 70 & 3 & 0.03 & 68.5 & 0.8562 & 0 & 137 \\
\hline 26 & Ormyrus pomaceus & 390 & 296 & 94 & -202 & 52.31 & 195 & $0.0000 * * *$ & 1 & 389 \\
\hline 27 & Pediobius rotundatus & 1 & 0 & 1 & 1 & 0.5 & 0.5 & 0.4795 & 0 & 1 \\
\hline 28 & Pediobius saulius & 4 & 3 & 1 & -2 & 2 & 2 & 0.4795 & 4 & 0 \\
\hline 29 & Reikosiella rostrata & 5 & 0 & 5 & 5 & 2.50 & 2.5 & 0.1138 & 2 & 3 \\
\hline 30 & Sycophila biguttata & 60 & 7 & 53 & 46 & 17.63 & 30 & $\mathbf{0 . 0 0 0 0} * * *$ & 1 & 59 \\
\hline 31 & Sycophila flavicollis & 315 & 36 & 279 & 243 & 93.73 & 157.5 & $0.0000 * * *$ & 1 & 314 \\
\hline 32 & Sycophila iracemae & 2 & 1 & 1 & 0 & 0.00 & 1 & 1.0000 & 0 & 2 \\
\hline 33 & Sycophila variegate & 55 & 10 & 45 & 35 & 11.14 & 27.5 & $0.0008 * * *$ & 0 & 55 \\
\hline 34 & Torymus auratus & 171 & 50 & 121 & 71 & 14.74 & 85.5 & $0.0001 * * *$ & 4 & 167 \\
\hline 35 & Torymus fastuosus & 15 & 6 & 9 & 3 & 0.30 & 7.5 & 0.5839 & 0 & 1 \\
\hline 36 & Torymus flavipes & 1917 & 608 & 1309 & 701 & 128.17 & 958.5 & $0.0000 * * *$ & 34 & 1897 \\
\hline 37 & Torymus formosus & 84 & 16 & 68 & 52 & 16.10 & 42 & $0.0001 * * *$ & 0 & 84 \\
\hline 38 & Torymus geranii & 1166 & 311 & 855 & 544 & 126.90 & 583 & $\mathbf{0 . 0 0 0 0} * * *$ & 2 & 1164 \\
\hline 39 & Torymus nobilis & 3 & 1 & 2 & 1 & 0.17 & 1.5 & 0.6831 & 0 & 3 \\
\hline 40 & Torymus notatus & 8 & 2 & 6 & 4 & 1.00 & 4 & 0.3173 & 0 & 8 \\
\hline \multirow[t]{2}{*}{41} & Torymus scutellaris & 3 & 1 & 2 & 1 & 0.17 & 1.5 & 0.6831 & 0 & 3 \\
\hline & Sum specimens & 11716 & 3951 & 7765 & & & & & 1260 & 10456 \\
\hline
\end{tabular}

The observed sex ratios were tested against the expected 50:50 ratio (all $\mathrm{DF}=1 ; * P<0.05 ; * * P<0.01 ; * * * P<0.001$ )

Symbology: sum specimens $=$ specimens of one species collected in our study; sum $\mathrm{m}$-male specimens collected; sum $\mathrm{f}$-female specimens collected; F-ratio—difference of number in favor of female specimens; chi2—Chi square test; exp 50/50—expected 50:50 sex ratio; sum oldspecimens collected from old (overwintered) ACGW galls; sum new-specimens collected from new (fresh) ACGW galls; $p$ value-statistical significance 
specimens was tested against a null hypothesis of a 50:50 sex ratio (Matošević and Melika 2013) to determine whether significant sex bias to any gender (e.g., more males or more females) existed in the sampled populations.

\section{Results}

Forty-one native parasitoid species emerged from the Asian chestnut gall wasp in Slovenia, Croatia and Hungary (Table 1). Eight of the 41 species were recorded for the first time on the ACGW in the countries in this study, and also represent the first records in Europe. Table 2 is a synoptic table of all ACGW parasitoid species in Europe with references to provide a complete list of all native parasitoids found on this new alien host. New records are in bold.

The emergence rates are provided for the seven most abundant species in Slovenia from 2010 to 2017 (Table 3), in Croatia (Table 4) and in Hungary (Table 5) from 2013 to 2015. The highest emergence rate in Slovenia was 5.0 by Torymus flavipes in 2011, followed by E. annulatus in 2014 (3.2) and E. urozonus in 2013 (2.5) (Table 3). Abundance indices peaked between 2011 and 2014. Based on the data from Slovenia, the absolute number of emerged specimens of native parasitoids fell from 1720 in 2014 to only 20 in 2017 (Fig. 1), while that of $T$. sinensis increased rapidly in this period (Table 3, Fig. 1).

Considering the effect of formational stage or age of the galls, 1,260 specimens of native parasitoids emerged from old, overwintered galls, while 10,456 specimens emerged from new, freshly formed galls (Table 1). This suggests that the first generation of native parasitoids, emerging in April-May, was successful in parasitizing ACGW in small but freshly formed galls, while the second generation (emerging in June-July) was far less successful in parasitizing ACGW in fully formed galls.

Overall, the most abundant species, with a number of emerged specimens over 1000, were E. urozonus (2149), T. flavipes (1917), B. dorsalis (1573), E. annulatus (1435), and $T$. geranii (1166) (Table 1). Several other species were present in lower amounts though most of the study period; e.g., E. brunniventris, E. pistaciae, M. sericeus, M. tibialis, O. nitidulus, O. pomaceus, and S. flavicollis. There were 19 species with only few recorded specimens (Table 1).

The most abundant native parasitoid in Slovenia and Croatia was T. flavipes, at 958 and 809 specimens, respectively, collected during the sampling period (2010-2017) which is similar to neighboring Italy (Santi and Maini 2011; Panzavolta et al. 2013, 2018; Francati et al. 2015; Ferracini et al. 2018), while the most abundant species in Hungary was E. urozonus (666), followed by B. dorsalis (375) and S. flavicollis (198) over all 3 years of collection (Table 5). Furthermore, in Slovenia the second highest number was $E$. annulatus (922), followed by E. urozonus (907), B. dorsalis (560) and O. pomaceus (337). On the other hand, in Croatia, over 5 years of collection (2013-2015 and based on data from Matošević and Melika (2013), the second most abundant species was T. geranii (786), followed by E. urozonus (571), M. sericeus (533) B. dorsalis (401), and E. annulatus (384). Interestingly, populations of the most common native parasitoids varied substantially over the years. In particular, populations of T. flavipes and E. urozonus in Slovenia fluctuated, while $M$. tibialis and $O$. pomaceus were abundant in the first years, but in the following years there were only a few specimens present (Table 3). In contrast, the population of $E$. annulatus increased through the years until the onset and expansion of the alien $T$. sinensis.

Our results show that the most abundant parasitoid species, Eupelmus urozonus, E. annulatus, Bootanomyia dorsalis, T. flavipes, and T. geranii also demonstrated femalebiased ratios with only one species having a male-biased sex ratio (Table 1).

The results of this study show the surge in abundance of native parasitoids and female-biased sex ratios during the study years (Tables 1 and 6). The bias was statistically significant between the years 2011 and 2015, marginally significant in 2016 and not significant from 2010 to 2017. Similar temporal patterns were observed regarding total yearly abundance.

\section{Discussion}

In the last two decades, a number of taxonomic revisions were made in different Chalcidoidea families, and new valid names and new synonymies established. Although they were neglected in the majority of papers on native parasitoids of ACGW, they were followed in this study: Eurytomidae, Eurytoma Illiger (Zerova and Seryogina 2009; Fusu 2013); Eupelmidae, Eupelmus Dalman (= Macroneura) (Fusu 2017), Reikosiella Yoshimoto (Al Khatib et al. 2014, 2016; Gibson and Fusu 2016); Torymidae, Torymus Dalman and Megastigmidae, Bootanomyia Girault (Doğanlar 2011; Janšta et al. 2017).

Our research shows that a rich parasitoid community has been formed on Asian chestnut gall wasp in Europe, which coincides with earlier studies (e.g., Matošević and Melika 2013; Melika et al. 2013). In the three countries covered by this study; 42 native parasitoid species, including Mesopolobus mediterranneus discovered by Jurc et al. (2013), from 13 genera and the alien $T$. sinensis were found on ACGW. Of these, eight are new records (Table 5), adding to the total of 51 native and one introduced species from 13 genera and six families known to parasitize Asian chestnut gall wasp in Europe. 
Table 2 List of parasitoids (native and non-native) on the Asian chestnut gall wasp (Dryocosmus kuriphilus) in Europe, with references of first records

\begin{tabular}{|c|c|c|c|}
\hline & Parasitoid species & Family & First record (author(s), year) \\
\hline 1 & Aprostocetus biorrhizae (Szelényi, 1941) & Eulophidae & Kos et al. (2015) \\
\hline 2 & Aprostocetus aethiops (Zetterstedt, 1838) & Eulophidae & Kos et al. (2015) \\
\hline 3 & Aprostocetus glandicola (Graham, 1987) & Eulophidae & Kos et al. (2015) \\
\hline 4 & Aulogymnus arsames (Walker, 1838) & Eulophidae & Quacchia et al. (2013) \\
\hline 5 & Aulogymnus skianeuros (Ratzeburg, 1844) & Eulophidae & Kos et al. (2015) \\
\hline 6 & Baryscapus pallidae (Graham, 1991) & Eulophidae & Aebi et al. (2006) \\
\hline 7 & Closterocerus trifasciatus (Westwood, 1833) & Eulophidae & First report Croatia \\
\hline 8 & Pediobius chilaspidis (Bouček, 1965) & Eulophidae & Quacchia et al. (2013) \\
\hline 9 & Pediobius rotundatus (Fonscolombe, 1832) & Eulophidae & First report Hungary \\
\hline 10 & Pediobius saulius (Walker, 1839) & Eulophidae & Quacchia et al. (2013) \\
\hline 11 & Eupelmus annulatus Nees, 1834 & Eupelmidae & Quacchia et al. (2013) \\
\hline 12 & $\begin{array}{l}\text { Eupelmus azureus Ratzeburg, } 1844 \text { (= Eupelmus spongipartus (Förster, } \\
1860) \text { ) }\end{array}$ & Eupelmidae & Quacchia et al. (2013) \\
\hline 13 & Eupelmus fulvipes Förster, 1860 & Eupelmidae & Quacchia et al. (2013) \\
\hline 14 & Eupelmus splendens Giraud, 1872 & Eupelmidae & Quacchia et al. (2013) \\
\hline 15 & Eupelmus urozonus Dalman, 1820 & Eupelmidae & Aebi et al. (2006) \\
\hline 16 & Eupelmus (=Macroneura) vesicularis (Retzius, 1783) & Eupelmidae & Kos et al. (2015) \\
\hline 17 & Reikosiella rostrata (Ruschka, 1921) & Eupelmidae & Boriani et al. (2013) \\
\hline 18 & Eurytoma adleriae (Zerova, 1995) & Eurytomidae & Quacchia et al. (2013) \\
\hline 19 & Eurytoma brunniventris (Ratzeburg, 1852) & Eurytomidae & Aebi et al. (2006) \\
\hline 20 & Eurytoma pistaciae $($ Rondani, 1877) $(=$ E. setigera $($ Mayr, 1878$)$ & Eurytomidae & Aebi et al. (2006) \\
\hline 21 & Sycophila biguttata (Swederus, 1795) & Eurytomidae & Aebi et al. (2006) \\
\hline 22 & Sycophila flavicollis (Walker, 1834) & Eurytomidae & Colombari and Battisti (2016) \\
\hline 23 & Sycophila iracemae (Nieves Aldrey, 1984) & Eurytomidae & Aebi et al. (2006) \\
\hline 24 & Sycophila variegata (Curtis, 1831) & Eurytomidae & Aebi et al. (2006) \\
\hline 25 & Ormyrus nitidulus (Fabricius, 1804) & Ormyridae & Quacchia et al. (2013) \\
\hline 26 & Ormyrus pomaceus (Geoffroy, 1785) & Ormyridae & Aebi et al. (2006) \\
\hline 27 & Cecidostiba fungosa (Geoffroy, 1785) & Pteromalidae & First report Croatia and Slovenia \\
\hline 28 & Cecidostiba semifascia (Walker, 1835) & Pteromalidae & Kos et al. (2015) \\
\hline 29 & Mesopolobus albitarsus (Walker, 1834) & Pteromalidae & Kos et al. (2015) \\
\hline 30 & Mesopolobus amaenus (Walker, 1834) & Pteromalidae & Quacchia et al. (2013) \\
\hline 31 & Mesopolobus dubius (Walker, 1834) & Pteromalidae & Matošević et al. (2013) \\
\hline 32 & Mesopolobus fasciiventris (Westwood, 1833) & Pteromalidae & Panzavolta et al. (2013) \\
\hline 33 & Mesopolobus lichtensteini (Mayr, 1903) & Pteromalidae & Jara-Chiquito et al. (2016) \\
\hline 34 & Mesopolobus mediterraneus (Mayr, 1903) & Pteromalidae & Aebi et al. (2006) \\
\hline 35 & Mesopolobus sericeus (Förster, 1770) & Pteromalidae & Aebi et al. (2006) \\
\hline 36 & Mesopolobus tarsatus (Nees, 1834) & Pteromalidae & Aebi et al. (2006) \\
\hline 37 & Mesopolobus tibialis (Westwood, 1833) & Pteromalidae & Quacchia et al. (2013) \\
\hline 38 & Mesopolobus xanthocerus (Thomson, 1878) & Pteromalidae & Pérez-Otero et al. (2017) \\
\hline 39 & Bootanomyia almusiensis (Doganlar, 1989) & Torymidae & Colombari and Battisti (2016) \\
\hline 40 & Bootanomyia dorsalis (Fabricius, 1798) & Torymidae & Aebi et al. 2006 \\
\hline 41 & Bootanomyia dumicola (Bouček, 1982) & Torymidae & First report Slovenia \\
\hline 42 & Bootanomyia stigmatizans (Fabricius, 1798) & Torymidae & First report Croatia \\
\hline 43 & Torymus auratus (Müller, 1764) & Torymidae & Aebi et al. (2006) \\
\hline 44 & Torymus erucarum (Schrank, 1781) & Torymidae & Speranza et al. (2009) \\
\hline 45 & Torymus fastuosus (Boheman, 1834) & Torymidae & First report Hungary \\
\hline 46 & Torymus flavipes (Walker, 1833) & Torymidae & Aebi et al. (2006) \\
\hline 47 & Torymus formosus (Walker, 1833) & Torymidae & Kos et al. (2015) \\
\hline 48 & Torymus geranii (Walker, 1833) & Torymidae & Matošević et al. (2013) \\
\hline
\end{tabular}


Table 2 (continued)

\begin{tabular}{llll}
\hline & Parasitoid species & Family & First record (author(s), year) \\
\hline 49 & Torymus nobilis (Boheman, 1834) & Torymidae & First report Hungary \\
50 & Torymus notatus (Walker, 1833) & Torymidae & First report Slovenia \\
51 & Torymus scutellaris (Walker, 1833) & Torymidae & Aebi et al. (2006) \\
& $*$ Torymus sinensis (Kamijo, 1982) & Torymidae & Aebi et al. (2007) \\
\hline
\end{tabular}

Table 3 Seven most common native parasitoids and alien T. sinensis on ACGW (Dryocosmus kuripilus) with standardized emergence rate in Slovenia in the period from 2010-2017

\begin{tabular}{|c|c|c|c|c|c|c|c|c|c|c|c|c|c|c|c|c|}
\hline \multirow[t]{2}{*}{ Slovenia } & \multicolumn{2}{|l|}{2010} & \multicolumn{2}{|l|}{2011} & \multicolumn{2}{|l|}{2012} & \multicolumn{2}{|l|}{2013} & \multicolumn{2}{|l|}{2014} & \multicolumn{2}{|l|}{2015} & \multicolumn{2}{|l|}{2016} & \multicolumn{2}{|l|}{2017} \\
\hline & $\mathrm{np}$ & er & $\mathrm{np}$ & er & $\mathrm{np}$ & er & $\mathrm{np}$ & er & $\mathrm{np}$ & er & $\mathrm{np}$ & er & $\mathrm{np}$ & er & $\mathrm{np}$ & er \\
\hline E.annulatus & 0 & 0.0 & 18 & 0.2 & 75 & 0.3 & 162 & 1.6 & 555 & 3.2 & 102 & 0.6 & 9 & 0.1 & 1 & 0.0 \\
\hline E. urozonus & 0 & 0.0 & 139 & 1.4 & 73 & 0.3 & 254 & 2.5 & 340 & 2.0 & 87 & 0.5 & 10 & 0.1 & 4 & 0.1 \\
\hline B. dorsalis & 1 & 0.0 & 83 & 0.8 & 66 & 0.3 & 14 & 0.1 & 240 & 1.4 & 152 & 0.8 & 1 & 0.0 & 3 & 0.0 \\
\hline M. tibialis & 0 & 0.0 & 119 & 1.2 & 9 & 0.0 & 0 & 0.0 & 77 & 0.4 & 0 & 0.0 & 0 & 0.0 & 1 & 0.0 \\
\hline O. pomaceus & 0 & 0.0 & 171 & 1.7 & 61 & 0.3 & 14 & 0.1 & 75 & 0.4 & 15 & 0.1 & 1 & 0.0 & 0 & 0.0 \\
\hline T. flavipes & 6 & 0.1 & 504 & 5.0 & 262 & 1.1 & 33 & 0.3 & 132 & 0.8 & 16 & 0.1 & 3 & 0.0 & 2 & 0.0 \\
\hline T. geranii & 2 & 0.0 & 20 & 0.2 & 13 & 0.1 & 32 & 0.3 & 43 & 0.3 & 42 & 0.2 & 0 & 0.0 & 0 & 0.0 \\
\hline other natives & 7 & 0.1 & 253 & 2.5 & 131 & 0.6 & 44 & 0.4 & 258 & 1.5 & 140 & 0.8 & 9 & 0.1 & 9 & 0.1 \\
\hline All native & 16 & 0.3 & 1307 & 13.0 & 690 & 3.0 & 553 & 5.5 & 1720 & 10.0 & 554 & 3.0 & 33 & 0.4 & 20 & 0.3 \\
\hline T. sinensis & $\mathbf{0}$ & 0.0 & $\mathbf{0}$ & 0.0 & $\mathbf{0}$ & 0.0 & $\mathbf{0}$ & 0.0 & $\mathbf{0}$ & 0.0 & 647 & 3.5 & 3162 & 40.0 & $\begin{array}{l}\text { Approx } \\
10000\end{array}$ & 146.9 \\
\hline ngy & 5072 & & 10030 & & 22841 & & 10002 & & 17131 & & 18473 & & 7909 & & 6809 & \\
\hline
\end{tabular}

Symbology: $\mathrm{np}=$ number of emerged parasitoids, er — standardized emergence rate, ngy—total number of analyzed galls per year

Table 4 Seven most common native parasitoids and alien T. sinensis on ACGW (Dryocosmus kuripilus) with standardized emergence rate in Croatia in the period from 2013 to 2015

\begin{tabular}{|c|c|c|c|c|c|c|}
\hline \multirow[t]{2}{*}{ Croatia } & \multicolumn{2}{|l|}{2013} & \multicolumn{2}{|l|}{2014} & \multicolumn{2}{|l|}{2015} \\
\hline & $\mathrm{np}$ & er & $\mathrm{np}$ & er & $\mathrm{np}$ & er \\
\hline E.annulatus & 14 & 0.3 & 150 & 5.1 & 149 & 1.03 \\
\hline E. urozonus & 255 & 4.9 & 122 & 4.2 & 161 & 1.12 \\
\hline B. dorsalis & 26 & 0.5 & 46 & 1.6 & 260 & 1.81 \\
\hline M. sericeus & 101 & 1.9 & 384 & 13.1 & 38 & 0.26 \\
\hline M. tibialis & 177 & 3.4 & 15 & 0.5 & 0 & 0.00 \\
\hline T. flavipes & 295 & 5.6 & 68 & 2.3 & 316 & 2.19 \\
\hline T. geranii & 366 & 7.0 & 71 & 2.4 & 214 & 1.49 \\
\hline other native & 171 & 3.3 & 531 & 18.1 & 395 & 2.74 \\
\hline All native & 1405 & 25.1 & 1387 & 34.7 & 1553 & 10.78 \\
\hline T. sinensis & $\mathbf{0}$ & $\mathbf{0}$ & 0 & $\mathbf{0}$ & 1041 & 7.23 \\
\hline ngy & 5252 & & 2936 & & 14401 & \\
\hline
\end{tabular}

Symbology: $\mathrm{np}=$ number of emerged parasitoids, er-standardized emergence rate, ngy—total number of analyzed galls per year
The most abundant species usually act as generalists, e.g., hosts of E. urozonus involve 32 families from five orders (Coleoptera, Diptera, Hemiptera, Hymenoptera and Lepidoptera), and E. annulatus and M. tibialis can parasitize hosts from three orders. In addition, $P$. saulius found in our research on ACGW galls can use hosts from 28 families of six different orders (Noyes 2018). It was also reported as most abundant parasitoid found in south-eastern Europe in the horse chestnut leaf miner, Cameraria ohridella Deschka \& Dimić (Lepidoptera: Gracillariidae), another invasive and abundant species (Grabenweger et al. 2010). 
Table 5 Total number of seven most common native parasitoids and alien $T$. sinensis on ACGW (Dryocosmus kuripilus) with standardized emergence rate in Hungary in the period from 2013 to 2015

\begin{tabular}{|c|c|c|c|c|c|c|}
\hline \multirow[t]{2}{*}{ Hungary } & \multicolumn{2}{|l|}{2013} & \multicolumn{2}{|c|}{2014} & \multicolumn{2}{|l|}{2015} \\
\hline & $\mathrm{np}$ & er & np & er & np & er \\
\hline E.annulatus & 0 & 0.0 & 0 & 0.0 & 57 & 0.4 \\
\hline E. urozonus & 296 & 18.5 & 238 & 28.0 & 132 & 0.01 \\
\hline B. dorsalis & 138 & 8,6 & 2 & 0.2 & 235 & 1.6 \\
\hline T. flavipes & 0 & 0.0 & 0 & 0.0 & 9 & 0.01 \\
\hline T. geranii & 7 & 0.4 & 38 & 4.5 & 121 & 0.8 \\
\hline Eurytoma brunniventris & 15 & 0.9 & 0 & 0.0 & 2 & 0.01 \\
\hline Sycophila flavicollis & 23 & 1.4 & 6 & 0.7 & 169 & 1.2 \\
\hline other native & 28 & 1.7 & 25 & 0.1 & 143 & 1.0 \\
\hline All native & 507 & 31.6 & 306 & 36 & 868 & 6.1 \\
\hline T. sinensis & $\mathbf{0}$ & 0.0 & $\mathbf{0}$ & 0.0 & & 0.0 \\
\hline Ngy & 1602 & & 850 & & 14203 & \\
\hline
\end{tabular}

Symbology: $\mathrm{np}=$ number of emerged parasitoids, er-standardized emergence rate, ngy—total number of analyzed galls per year

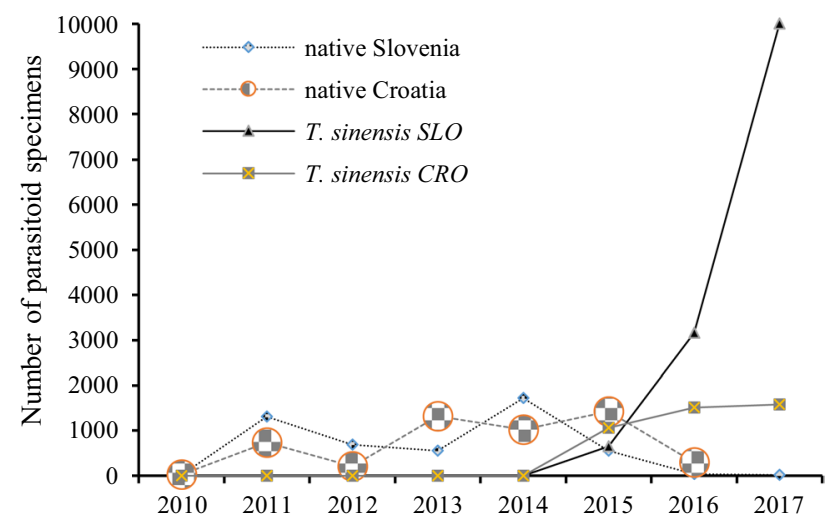

Fig. 1 Number of native parasitoids and alien T. sinensis specimens on ACGW found in Slovenia (2010-2017) and Croatia (2010-2016)
It has been shown that seasonal asynchrony between ACGW and native parasitoids could have an indirect impact on the native hosts that share the same parasitoids with abundant alien pests (Budroni et al. 2018). Although parasitism rates of ACGW by native parasitoids generally remain low (Aebi et al. 2011), some studies have shown rates of over 30\% (Santi and Maini 2011; Panzavolta et al. 2018). In cases where these two coincide, significantly higher pressure of native parasitoids on their primary native hosts (e.g., oak cynipids) can occur since the second generation of parasitoids, now more numerous due to additional progeny from the newly adopted host, can parasitize only the asexual generation of its primary native host (e.g., oak gall wasps) (Budroni et al. 2018).

A similar scenario was noted in the case of another invasive pest, the horse chestnut leaf-miner ( $C$. ohridella), where over 30 species of native parasitoids were found, although in low parasitizing rates (Stojanović and Marković 2004; Ferracini and Alma 2007; Grabenweger et al. 2010). However,
Table 6 Number of native parasitoids emerged from ACGW from Slovenia, Croatia and Hungary from 2010 to 2017, with sex ratio and sex bias test

\begin{tabular}{lrrrccrl}
\hline Year & \multicolumn{1}{c}{ sum } & $\mathrm{m}$ & $\mathrm{f}$ & F-ratio & $\exp 50 / 50$ & chi2 & $p$ value \\
\hline 2010 & 42 & 13 & 29 & 16 & 21 & 3.05 & 0.0809 \\
2011 & 2041 & 731 & 1310 & 579 & 1020.5 & 82.13 & $0.0000^{* * *}$ \\
2012 & 895 & 353 & 542 & 189 & 447.5 & 19.96 & $0.0000^{* * *}$ \\
2013 & 2233 & 725 & 1508 & 783 & 1116.5 & 137.28 & $0.0000^{* * *}$ \\
2014 & 3108 & 1086 & 2022 & 936 & 1554 & 140.94 & $0.0000^{* * *}$ \\
2015 & 2997 & 860 & 2137 & 1277 & 1498.5 & 272.06 & $0.0000^{* * *}$ \\
2016 & 331 & 126 & 205 & 79 & 165.5 & 9.43 & $0.0021^{* *}$ \\
2017 & 20 & 6 & 14 & 8 & 10 & 1.60 & 0.2059 \\
\hline
\end{tabular}

The observed sex ratios were tested against the expected 50:50 ratio (all $\mathrm{DF}=1 ; * P<0.05 ; * * P<0.01$; $* * * P<0.001)$

Symbology: sum =number of specimen collected; $\mathrm{m}$-number of males; $\mathrm{f}$-number of females; F-ratiodifference of number in favor of female specimens; exp 50/50 - expected 50:50 sex ratio; chi2—Chi square test; $p$ value-statistical significance 
many species of native parasitoids can build up their numbers on a new host early in the spring, resulting in exposure of later-occurring native leaf-miners to a greater pressure of parasitoids (Péré et al. 2010).

Our data shows the surge in population numbers of native parasitoids attacking Asian chestnut gall wasp from 2010 to 2015. This suggests that native parasitoids were gradually adapting to their new host, and perhaps could have led to ecological consequences described by Budroni et al. (2018). However, the abundance of native parasitoids on ACGW dropped dramatically after the onset of $T$. sinensis and its outbreak since 2016 (Fig. 1). This highlights the success of this specialized parasitoid in attacking the Asian chestnut gall wasp (Matošević et al. 2017), and indicates that it possibly outcompeted the native parasitoids which were adapting to the new host. The differences in the number of T. sinensis in Slovenia and Croatia in 2016 and 2017 are due to rapid, natural spread in Slovenia and the vicinity to Italy, and a slower natural spread in Croatia with a larger distance to Italy (Matošević et al. 2017).

The only effective parasitoid from the native range of $T$. sinensis is phenologically well synchronized with its specific host ACGW. It is also univoltine and may undergo prolonged diapause, and females emerge from overwintered galls of ACGW in spring, right in the time of gall formation (Moriya et al. 1990). It quickly establishes populations, reaches high parasitism rates and has good dispersal abilities, so it effectively controls the ACGW a few years after the release (Matošević et al. 2015, 2017; Avtzis et al. 2019; Ferracini et al. 2019).

Recent studies demonstrated that the introduction of parasitoid $T$. sinensis, along with the absence of oak, caused the loss of about $14 \%$ of native parasitoid species on Asian chestnut gall wasp, commonly associated with oak gall wasps, and $32 \%$ of their population density (Ferracini et al. 2018). Their results indicate that the introduction of $T$. sinensis affects the richness of native parasitoids on ACGW. The results from Slovenia show that parasitism rates of native parasitoid species were high from 2010 to 2014 compared to the years before and after this period. Rapid decrease in parasitism rates of native parasitoid species corresponded with the onset of T. sinensis in 2015 and its massive population growth in later years (Table 3, Fig. 1). In addition, the number of native species was reduced from a maximum 23 in 2014 to 9 in 2017. In Slovenia, the exotic T. sinensis reached standardized emergence rates of 3.5 in 2015, 39.9 in 2016, and over 140 in 2017 (Table 3). It may be hypothesized that $T$. sinensis has already spread before first releases in Slovenia in 2015 (Jurc et al. 2017; Matošević et al. 2017). T. sinensis had also the highest emergence rate in 2015 in Croatia (Table 4), which corresponds with its rapid spread from Italy to Slovenia (Matošević et al. 2017). No specimens of $T$. sinensis were found in samples from Hungary, which may be due to no established populations prior to 2015. The first release of this biocontrol agent were carried out in 2014 and 2015, and a slower natural spread due to geographical distance from Italy (Matošević et al. 2017).

The presence of abundant populations of $T$. sinensis emerging from overwintered galls renders the fresh ACGW galls effectively unavailable for native parasitoids, thus impairing their opportunity to grow.

The female-biased sex ratio (Tables 1 and 6) is in agreement that parasitoids with female-biased sex ratios are more valuable for biological control, as only females are directly responsible for killing pests by oviposition, so the parasitoid population growth primarily depends on the number of females (Hall 1993; Ode and Heinz 2002).

Only one species, Ormyrus pomaceus, demonstrated significant male-biased sex ratios ( $75 \%$ of all specimens were males). This differs from equal ratios reported for Croatia in 2011 (Matošević and Melika 2013) altough in that study the researchers collected only four specimens of these parasitoids. The reasons for male-biased ratios of $O$. pomaceus found in this research remain unanswered, and it would be useful to investigate the reproductive traits of this parasitoid.

Considering the impact of the Asian chestnut gall wasp on the stability of forest ecosystems in Europe in light of the potential direct and indirect consequences of invasions (Ives and Carpenter 2007), the influence of well-synchronized and effective parasitoid $T$. sinensis should be considered for the maintenance of ecological balance which are directly and/ or indirectly affected by ACGW.

In a long term perspective, and considering the dynamics of native parasitoids' cycles, native parasitoids could be effective as integrative agents to $T$. sinensis which emerges during a single period (Heimpel and Mills 2017).

Acknowledgements We would like to thank Blaženka Ercegovac for help in collecting galls and laboratory work.

Open Access This article is licensed under a Creative Commons Attribution 4.0 International License, which permits use, sharing, adaptation, distribution and reproduction in any medium or format, as long as you give appropriate credit to the original author(s) and the source, provide a link to the Creative Commons licence, and indicate if changes were made. The images or other third party material in this article are included in the article's Creative Commons licence, unless indicated otherwise in a credit line to the material. If material is not included in the article's Creative Commons licence and your intended use is not permitted by statutory regulation or exceeds the permitted use, you will need to obtain permission directly from the copyright holder. To view a copy of this licence, visit http://creativecommons.org/licenses/by/4.0/.

\section{References}

Aebi A, Schonrogge K, Melika G, Alma A, Bosio G, Quacchia A, Picciau L, Abe Y, Moriya S, Yara K, Seljak G, Stone GN (2006) Parasitoid recruitment to the globally invasive chestnut gall wasp 
Dryocosmus kuriphilus. In: Ozaki K, Yukwa J, Ohgushi T, Price PW (eds) Ecology and evolution of galling arthropods and their associates. Springer, Tokyo, pp 103-121

Aebi A, Schonrogge K, Melika G, Quacchia A, Alma A, Stone GN (2007) Native and introduced parasitoids attacking the invasive chestnut gall wasp Dryocosmus kuriphilus. EPPO Bull 37:166-171

Aebi A, Schönenberger N, Bigler F (2011) Evaluating the use of Torymus sinensis against the chestnut gall wasp Dryocosmus kuriphilus in the Canton Ticino, Switzerland. Agroscope ReckenholzTänikon Report

Al Khatib F, Fusu L, Cruaud A, Gibson G, Borowiec N, Rasplus JY, Ris N, Delvare G (2014) An integrative approach to species discrimination in the Eupelmus urozonus complex (Hymenoptera, Eupelmidae), with the description of 11 new species from the Western Palaearctic. Syst Entomol 39:806-862

Al Khatib F, Cruaud A, Fusu L, Genson G, Rasplus JY, Ris N, Delvare $\mathrm{G}$ (2016) Multilocus phylogeny and ecological differentiation of the "Eupelmus urozonus species group" (Hymenoptera, Eupelmidae) in the West-Palaearctic. BMC Evolut Biol 16:13

Antolin MF, Bjorksten TA, Vaughn TYT (2006) Host-related fitness trade-off in a presumed generalist parasitoid, Diaeretiella rapae (Hymenoptera:Aphidiidae). Ecol Entomol 31:242-254

Askew RR, Melika G, Pujade-Villar J, Schönrogge K, Stone GN, Nieves-Aldrey JL (2013) Catalogue of parasitoids and inquilines in cynipid oak galls in the West Palaearctic. Zootaxa 3643:1-133

Avtzis DN, Melika G, Matošević D, Coyle DR (2019) The Asian chestnut gall wasp Dryocosmus kuriphilus: a global invader and a successful case of classical biological control. J Pest Sci 92:107-115

Boriani M, Molinari M, Bazzoli M (2013) Orthopelma mediator (Thunberg) (Hymenoptera: Ichneumonidae) and the native parasitoid complex of Dryocosmus kuriphilus Yasumatsu (Hymenoptera: Cynipidae) in Lombardy (Italy). Entomofauna 34:201-204

Budroni MA, Loru L, Pantaleoni RA, Rustici M (2018) Effects of an asynchronous alien host on a native host-parasitoid system. Ecol Complex 33:84-92

Colombari F, Battisti A (2016) Native and introduced parasitoids in the biocontrol of Dryocosmus kuriphilus in Veneto (Italy). EPPO Bull 46:275-285

Desneux N, Barta ERJ, Hoelmer EKA, Hopper EKR, Heimpel EGE (2009) Multifaceted determinants of host specificity in an aphid parasitoid. Oecologia 160:387-398

Doğanlar M (2011) Review of Palearctic and Australian species of Bootanomyia Girault 1915 (Hymenoptera: Torymidae: Megastigminae), with descriptions of new species. Turk J Zool 35:123-157

EPPO (2005) Dryocosmus kuriphilus. EPPO Bull 35:422-424

Ferracini C, Alma A (2007) Evaluation of the community of native eulophid parasitoids on Cameraria ohridella Deschka and Dimic in urban areas. Environ Entomol 36:1147-1153

Ferracini C, Bertolino S, Bernardo U, Bonsignore CP, Faccoli M, Ferrari E, Lupi D, Maini S, Mazzon L, Nugnes F, Rocco A, Santi F, Tavella L (2018) Do Torymus sinensis (Hymenoptera: Torymidae) and agroforestry system affect native parasitoids associated with the Asian chestnut gall wasp? Biol Control 121:36-43

Ferracini C, Ferrari E, Pontini M, Saladini MA, Alma A (2019) Effectiveness of Torymus sinensis: a successful long-term control of the Asian chestnut gall wasp in Italy. J Pest Sci 92:353-359

Francati S, Alma A, Ferracini C, Pollini A, Dindo ML (2015) Indigenous parasitoids associated with Dryocosmus kuriphilus in a chestnut production area of Emilia Romagna (Italy). Bull Insectol 68:127-134

Fusu L (2013) A revision of the Palaearctic species of Reikosiella (Hirticauda) (Hymenoptera, Eupelmidae). Zootaxa 3636:1-34

Fusu L (2017) An integrative taxonomic study of European Eupelmus (Macroneura) (Hymenoptera: Chalcidoidea: Eupelmidae), with a molecular and cytogenetic analysis of Eupelmus (Macroneura) vesicularis: several species hiding under one name for 240 years. Zool J Linn Soc 181:519-603

Gibson GAP, Fusu L (2016) Revision of the palaearctic species of Eupelmus (Eupelmus) Dalman (Hymenoptera: Chalcidoidea: Eupelmidae). Zootaxa 4081:001-331

Godfray HCJ (1994) Parasitoids behavioral and evolutionary ecology. Princeton University Press Books, Princeton, p 488

Goulet H, Huber JT (1993) Hymenoptera of the world: an identification guide to families. Agriculture Canada, Ottawa, Ontario, p 680

Grabenweger G, Kehrli P, Zweimuller I, Augustin S, Avtzis N, Bacher S, Freise J, Girardoz S, Guichard S, Heitland W, Lethmayer C, Stolz M, Tomov R, Volter L, Kenis M (2010) Temporal and spatial variations in the parasitoid complex of the horse chestnut leafminer during its invasion of Europe. Biol Invasions $12: 2797-2813$

Hall RW (1993) Alteration of sex ratios of parasitoids for use in biological control. In: Wrensch DL, Ebbert MA (eds) Evolution and diversity of sex ratio in insects and mites. Chapman \& Hall, New York, pp 542-547

Heimpel GE, Mills NJ (2017) Biological control: ecology and applications. Cambridge University Press, Cambridge

Henry LM, Roitbergand BD, Gillespie DR (2008) Host-range evolution in Aphidius parasitoids: fidelity, virulence and fitness tradeoffs on an ancestral host. Evolution 62:689-699

Ives A, Carpenter S (2007) Stability and diversity of ecosystems. Science 317:58-62

Janšta P, Cruaud A, Delvare G, Genson G, Heraty J, Křižkova B, Rasplus JY (2017) Torymidae (Hymenoptera, Chalcidoidea) revised: molecular phylogeny, circumscription and reclassification of the family with discussion of its biogeography and evolution of life-history traits. Cladistics 34:627-651

Jara-Chiquito JL, Heras J, Pujade-Villar J (2016) Primeros datos de reclutamiento de himenópteros parasitoides autóctonos para Dryocosmus kuriphilus Yasumatsu (Hymenoptera: Cynipidae) en Cataluña (Península Ibérica). Bol SEA 59:219-226

Jurc M, Mihajlović L, Fernández MF, Borkovič D (2013) Differences in occurrence of Dryocosmus kuriphilus parasitoids depend on time on chestnut gallwasp introduction to Slovenia and Spain. In: Radócz L (ed) Proceedings of II. European Congress on Chestnut, Debrecen, Hungary, pp 9-12

Jurc M, Bojović S, Jurc D (2017) Non-native insects in urban and forest areas of Slovenia and the introduction of Torymus sinensis with Dryocosmus kuriphilus. Open J For 07(04):416-427

Kos K, Kriston E, Melika G (2015) Invasive chestnut gall wasp Dryocosmus kuriphilus (Hymenoptera: Cynipidae) its native parasitoid community and its association with oak gall wasps in Slovenia. Eur J Entomol 112:698-704

Kos K, Melika G, Celar FA (2017) Native parasitoids of Chestnut gall wasp (Dryocosmus kuriphilus Yasumatsu) and other cynipids in Slovenia (2010-2016). In: Trdan S (ed) Lectures and papers presented at the 13th Slovenian conference on plant protection with international participation, Rimske Toplice, March 7-8, pp 206-211

Kriston E, Matošević D, Kos K, Seljak G, Bosio G, Quacchia A, Krizbai L, Bozsó M, Csóka G, Melika G (2014) Native parasitoid assemblages of chestnut gallwasp, Dryocosmus kuriphilus (Hym.: Cynipidae) in Europe. In: VII congress on plant protection, Zlatibor (Serbia), pp 24-28

Matošević D, Melika G (2013) Recruitment of native parasitoids to a new invasive host: first results of Dryocosmus kuriphilus parasitoid assemblage in Croatia. Bull Insectol 66:231-238

Matošević D, Lacković N, Melika G, Kos K, Franić I, Kriston É, Bozsó M, Seljak G, Rot M (2015) Biological control of invasive Dryocosmus kuriphilus with introduced parazitoid Torymus sinensis in Croatia, Slovenia and Hungary. Period Biol 4:471-477 
Matošević D, Lacković N, Kos K, Kriston É, Melika G, Rot M, Pernek M (2017) Success of classical biocontrol agent Torymus sinensis within its expanding range in Europe. J Appl Entomol 141:758-767

Melika G, Matošević D, Kos K, Bosio G, Kriston É, Krizbai L, Bozsó M, Csóka G, Pénzes Z, Quacchia A (2013) Native parasitoids attacking the Chestnut Gallwasp, Dryocosmus kuriphilus (Hymenoptera: Cynipidae), across Italy-Slovenia-Croatia-Hungary. In: II. European congress on chestnut, pp 09-12

Moriya S, Inoue K, Mabuchi M (1990) The use of Torymus sinensis (Hymenoptera, Torymidae) for controlling the chestnut gall wasp, Dryocosmus kuriphilus (Hymenoptera, Cynipidae), in Japan. FFTC-NARC International Seminar on The use of parasitoids and predators to control agricultural pests', $\mathrm{p} 21$

Noyes JS (2018) Universal Chalcidoidea Database. World Wide Web electronic publication. http://www.nhm.ac.uk/chalcidoids. Accessed 10 December 2018

Ode PJ, Heinz KM (2002) Host-size-dependent sex ratio theory and improving mass-reared parasitoid sex ratios. Biol Control $24: 31-41$

Ôtake A (1989) Chestnut gall wasp, Dryocosmus kuriphilus YASUMATSU (Hymenoptera: Cynipidae): analyses of records on cell contents inside galls and on emergence of wasps and parasitoids outside galls. Appl Entomol Zool 24(52):193-201

Panzavolta T, Bernardo U, Bracalini M, Cascone P, Croci F, Gebiola M (2013) Native parasitoids associated with Dryocosmus kuriphilus in Tuscany, Italy. Bull Insectol 66:195-201

Panzavolta T, Croci F, Bracalini M, Tiberi R, Melika G, Benedettelli S, Tellini FG (2018) Population dynamics of native parasitoids associated with the Asian chestnut gall wasp (Dryocosmus kuriphilus) in Italy. Psyche 2:1-13

Péré C, Augustin S, Tomov R, Peng L, Turlings TCJ, Kenis M (2010) Species richness and abundance of native leaf miners are affected by the presence of the invasive horse-chestnut leaf miner. Biol Invasions 12:1011-1021

Pérez-Otero R, Crespo D, Mansilla JP (2017) Dryocosmus kuriphilus Yasumatsu, 1951 (Hymenoptera: Cynipidae) in Galicia (NW Spain): pest dispersion, associated parasitoids and first biological control attempts. Arq Entomol 17:439-448

Quacchia A, Ferracini C, Nicholls JA, Piazza E, Saladini MA, Tota F, Melika G, Alma A (2013) Chalcid parasitoid community associated with the invading pest Dryocosmus kuriphilus in northwestern Italy. Insect Conserv Divers 6:114-123

Santi F, Maini S (2011) New association between Dryocosmus kuriphilus and Torymus flavipes in chestnut trees in the Bologna area (Italy): first results. Bull Insectol 64:275-278

Speranza S, Stacchiotti M, Paparatti B (2009) Endemic parasitoids of Dryocosmus kuriphilus Yasumatsu. (Hymenoptera: Cinipidae) in central Italy. Acta Hortic 844:421-424

Stojanović A, Marković C (2004) Parasitoid complex of Cameraria ohridella (Lepidoptera: Gracillariidae) in Serbia. Phytoparasitica 32:132-140

Zepeda-Paulo FA, Ortiz-Martínez SA, Figueroa CC, Lavandero B (2013) Adaptive evolution of a generalist parasitoid: implications for the effectiveness of biological control agents. Evol Appl 6:983-999

Zerova MD, Seryogina LY (2009) A review of Eurytoma pistaciae species group (Hymenoptera, Eurytomidae), with description of two new species. Vestn Zool 43:31-38

Publisher's Note Springer Nature remains neutral with regard to jurisdictional claims in published maps and institutional affiliations. 